\title{
Analysis on the Impact of Zhengzhou-Xi'an High Speed Railway on Local Economy
}

\author{
Qiangwei Wen 1, a, Canli Qiao ${ }^{1, \text { b }}$, Jian Jiang 2, c, * \\ 1. China Railway Zhengzhou Bureau Co., Ltd, Zhengzhou, 450000, China \\ 2. School of Traffic and Transportation, Beijing Jiaotong University, Beijing 100044, China \\ a 13598085998@139.com, b15838020666@139.com, c, “jjiang@bjtu.edu.cn
}

\begin{abstract}
This paper analyzes the ways and mechanism of the impact of high-speed railway on local economy, and summarizes the impact of the construction and operation of high-speed railway on local economy as four positive effects: agglomeration effect, diffusion effect, urbanization and regional economic integration, and a negative effect of siphon effect. Taking Zhengxi high-speed railway as an example, using different quantitative calculation methods, this paper analyzes the three effects of agglomeration effect, diffusion effect and urbanization, and finds that the accessibility and economic volume of cities along the line have been greatly improved before and after the opening of high-speed railway.
\end{abstract}

Keywords: Agglomeration Effect; Diffusion Effect; Urban Integration.

\section{Introduction}

The development of regional economy is inseparable from the take-off of transportation industry. Throughout the history of transportation development at home and abroad, it is not difficult to find that convenient transportation plays an indispensable role in regional development. On the one hand, it can improve regional accessibility and speed up the flow of market factors; On the other hand, convenient transportation promotes the internal and external economic cycle of the region and injects new vitality into regional development.

For literature review, FEMAND Martin [1] pointed out that the construction of high-speed railway can greatly promote the improvement of transportation capacity along the line and optimize the allocation of transportation resources. U. Blum [2] and others believe that many cities and regions along the high-speed railway are connected by high-speed railway, their accessibility has been improved, and a comprehensive functional area or economic corridor has been formed. David Ellis [3] built a traffic demand model, predicted various benefits brought by the construction of high-speed railway to Tennessee, such as time benefits, accessibility benefits, etc., and came to the conclusion that high-speed railway will promote the economic development of Tennessee. Tim Lynch [4] took Florida as an example, studied its high-speed railway corridor, and found that the construction of high-speed railway attracted passengers from some expressways and civil aviation, and reduced energy consumption. Reed [5] focused on the relationship between high-speed railway system and important activity space and studied its system benefits. These key activity spaces mainly include business centers, logistics centers, theme parks and other areas where people gather. Goossens [6] set the road network conditions as quantitative and the train stop scheme as variable, and analyzed the method of formulating periodic train operation scheme. The author establishes a mixed integer programming model and makes a quantitative calculation with the single objective of minimizing the operating cost. The main research object of Eisele [7] is suburban commuter railway train, and its stop mode is divided into station stop, large station stops and regional stop. Then the passenger flow demand is analyzed. The results show that suburban commuter railway is more suitable for regional stop mode. Schobel [8] established the optimization model of the operation scheme. The optimization objective is to minimize the passenger time, creatively consider the time required for passenger transfer, and then study the model through the decomposition algorithm.

This paper summarizes four theories related to transportation and regional economy, such as growth pole theory and point axis development theory, briefly introduces the definition of high-speed 
railway and its technical and economic advantages, summarizes the mechanism of the impact of highspeed railway on local economy in three aspects: optimizing regional industrial structure and spatial structure, and summarizes its specific impact as agglomeration effect, diffusion effect Then it introduces the quantitative analysis methods for the three effects of agglomeration effect, diffusion effect and urbanization. Taking Zhengxi high-speed railway as an example, the empirical analysis is mainly carried out from four aspects. Firstly, the value input-output model is used to calculate the agglomeration effect of Zhengxi high-speed railway on industries along the line. It is found that the completion of Zhengxi high-speed railway has a strong agglomeration effect on many industries in Henan Province and Shaanxi Province; Secondly, using the deviation share space structure model, this paper calculates the social benefits brought by the industrial diffusion effect of Zhengxi highspeed railway along the line; Thirdly, by calculating the favorable average travel time of major cities along the Zhengzhou West high speed railway, the accessibility changes of major cities along the railway before and after the opening of the high speed railway are measured. The results show that the accessibility of major cities is improved greatly.

\section{Influence Mechanism of High Speed Railway on Local Economy Case Study}

The specific impact of high-speed railway on local economy is summarized into 3 aspects: agglomeration effect, diffusion effect, and urbanization.

\subsection{Agglomeration Effect}

The phenomenon of industrial agglomeration comes into being with the development of social division of labor. Its purpose is mainly to create agglomeration effect for economic development and strengthening the competitiveness of local enterprises. As a whole, it is reflected in the formation of geographical spatial agglomeration of industries.

The high-speed railway mainly affects the industrial agglomeration effect through the following three aspects: first, the high-speed railway rapid transportation mode will avoid the traditional slow transportation or the use of expensive means of air transportation, resulting in the saving of enterprise costs. Second, the high-speed railway can effectively enhance the interrelatedness of regions. The companies in the region can not only use the high-speed railway to quickly obtain raw materials, but also quickly send them to the market, which speeds up the capital turnover and meets the development needs of the company. Third, due to its passenger transport advantages, high-speed railway has attracted some passenger flow of ordinary speed railway, alleviated its passenger transport pressure, released some transport capacity and improved the industrial transport structure, which will well improve the level of train freight transport and promote the optimization and upgrading of industry, so as to make the railway occupy a larger market in the comprehensive transport system and lay out more enterprises along the railway and nodes. This agglomeration effect can promote the development of regional economy.

\subsection{Diffusion Effect}

With the continuous development and expansion of the economic center, it will gradually radiate to the surrounding areas, promote their development and narrow the difference between the two. This effect is the diffusion effect. The basis of diffusion effect is the flow of resource factors and means of production, and its impact also depends on the depth and breadth of these factors. By increasing the construction of transportation, we can effectively improve the connection between the economic center and the surrounding areas, play a better radiation effect, strengthen economic cooperation and exchange, and fully drive the economic cooperation of the whole region to complement each other, make common progress and develop together.

At present, the effects of high-speed railway on industrial diffusion are mainly reflected in the following aspects: first, the construction of high-speed railway will effectively drive the flow of various resources and materials and increase the good diffusion effect. It will complement the 
resources and talents of big cities and surrounding small cities. Through high-speed railway, the elements of big cities can flow more easily to small and medium-sized cities, accelerating the economic development and talent circulation of small cities. Second, population congestion and increased costs will lead to radial diffusion. If a large population stays in a big city, it will not only cause a series of urban diseases, which is not conducive to its economic development, but also increase the cost burden for residents and enterprises in the city. The increase of cost forces enterprises to spread to small and medium-sized cities. This layout not only solves the problem of virtual high cost, but also improves the attraction of areas along the high-speed railway.

\subsection{Urbanization}

Co urbanization means that with the continuous improvement of transportation conditions, cities integrate and promote each other in all aspects. Co urbanization is not a simple expansion of urban scale, but a plate economy formed by continuous radiation, diffusion and competition. The production factors of each city continue to flow and allocate in the urban agglomeration, and the spatial structure continues to improve, forming a metropolitan economy.

Transportation infrastructure effectively ensures the coordinated development of the same city, that is, to realize the same city. With the continuous development and progress of the city, the transportation is more and more convenient, and the flow of population and capital becomes very frequent. As a result, the mutual cooperation between cities is deepened, so it is easier to appear the metropolitan economic development circle. High speed railway transportation is fast and convenient, which can not only effectively ensure people's travel and commuting, but also enhance the efficient connection between cities and deepen the economic integration and development of cities.

Favorable average travel time is an important index to evaluate the time distance from a node to other nodes, which is determined by the geographical location, economic strength and transportation conditions from the node to another node. The better the geographical location of the node, the stronger the economic strength and the more convenient the transportation with other nodes, the lower the favorable average travel time, which means the higher its accessibility.

\section{Methodology}

This paper adopts the deviation share spatial structure model to analyze the impact of high-speed railway on regional industrial diffusion effect. Static deviation share model is an analytical method to analyze the change of industrial structure. The disadvantage is that only considering the changes of industrial structure and competitive advantage in the base year during the survey period, excluding the continuous changes during the survey period, it is impossible to reveal the contribution to the total deviation during the survey period. Compared with the static deviation share model, the dynamic deviation share model introduces the dynamic idea into the dynamic model to calculate the industry change in each period. It is not difficult to see that this model belongs to a dynamic model, which mainly adds the elements of spatial weight matrix in the model, which can quantitatively analyze the spatial connection strength of regional industries, and is characterized by the ability to carry out relevant dynamic research on the regional economic development of industrial units.

The original deviation share model will decompose the growth of regional industry into three elements, followed by the share component $W_{i j}$. Industrial structure component $S_{i j}$ and competitiveness component $C_{i j}$. At the same time, the share component $W_{i j}$ refers to the increment generated according to the average growth rate of various domestic industries; Industrial structure component $S_{i j}$ represents the increment caused by the difference between the corresponding evaluation growth rate of the $\mathrm{j}$ industry and the domestic average growth rate in region $\mathrm{i}$, which can explain the corresponding growth rate of the $\mathrm{j}$ industry and the domestic average level; Competitiveness component $C_{i j}$ represents the difference between the regional $i$ growth rate of industry $\mathrm{j}$ and the average growth rate of domestic industry $\mathrm{j}$, indicating the average level of this industry and domestic industry in this region. 
Volume 17 (2022)

The calculation expression of each component is as follows:

$$
\begin{gathered}
W_{i j}=X_{i j}^{0} \cdot l \\
S_{i j}=X_{i j}^{0} \cdot\left(l_{j}-l\right) \\
C_{i j}=C_{i j} \cdot\left(l_{i j}-l_{j}\right)
\end{gathered}
$$

Where: $X_{i j}^{0}(\mathrm{i}=1,2, \ldots, \mathrm{m} ; \mathrm{j}=1,2, \ldots, \mathrm{n})$ - the initial economic volume of the $\mathrm{j}$ industry in region $\mathrm{i}$; $l$ - standard growth rate;

$l_{j}$ - growth rate of structural effect of the $\mathrm{j}$-th industry;

$l_{i j}$ - the actual growth rate of the tertiary industry in region $i$.

The economic increment $\mathrm{Zij}$ in period $\mathrm{T}$ is:

$$
Z_{i j}=W_{i j}+S_{i j}+C_{i j}
$$

Where: $X_{i j^{-}}^{\mathrm{t}}$ the economic volume of industry $\mathrm{j}$ in region $\mathrm{i}$ at the end of period $\mathrm{T}$.

Of which:

$$
\begin{array}{r}
l_{j}=\sum_{\mathrm{j}=1}^{\mathrm{n}}\left(X_{i j}^{\mathrm{t}}-X_{i j}^{0}\right) / \sum_{\mathrm{j}=1}^{\mathrm{n}} X_{i j}^{0} \\
l_{i j}=\left(X_{i j}^{\mathrm{t}}-X_{i j}^{0}\right) / X_{i j}^{0}
\end{array}
$$

By adding the spatial weight matrix into the original model, we can more comprehensively consider the reasons for spatial growth, and then analyze the characteristic process of the dynamic structure caused by industrial units to regional economic development according to the data information.

\section{Case Study}

Table 1. Added Value of Transportation, Storage, Postal Service and Real Estate Industry

\begin{tabular}{|c|c|c|c|c|}
\hline Region & $\begin{array}{c}\text { Added value of } \\
\text { transportation, storage } \\
\text { and postal industry from } \\
\mathbf{2 0 0 7} \text { to 2009 }\end{array}$ & $\begin{array}{c}\text { Added value of } \\
\text { real estate } \\
\text { industry from } \\
\mathbf{2 0 0 7} \text { to 2009 }\end{array}$ & $\begin{array}{c}\text { Added value of } \\
\text { transportation, storage } \\
\text { and postal industry from } \\
\mathbf{2 0 1 0} \text { to 2012 }\end{array}$ & $\begin{array}{c}\text { Added value of } \\
\text { real estate } \\
\text { industry from } \\
\mathbf{2 0 1 0} \text { to 2012 }\end{array}$ \\
\hline Zhengzhou & 644.81 & 382.35 & 868.03 & 680.42 \\
\hline Luoyang & 317.03 & 112.2 & 337.82 & 227.02 \\
\hline Sanmenxia & 150.45 & 22.49 & 209.76 & 31.57 \\
\hline Weinan & 49.64 & 49.07 & 73.85 & 94.74 \\
\hline Xi'an & 292.5 & 289.82 & 461.75 & 592.35 \\
\hline
\end{tabular}

Table 2. Spatial Deviation -Share Value

\begin{tabular}{|c|c|c|c|c|c|c|c|c|}
\hline \multirow{2}{*}{ Region } & \multicolumn{6}{|c|}{ Transportation, storage and postal industry } & \multicolumn{4}{c|}{ Real estate industry } \\
\cline { 2 - 9 } & $\mathrm{W}_{\mathrm{ij}}$ & $\mathrm{S}_{\mathrm{ij}}$ & $\mathrm{C}_{\mathrm{ij}}$ & $\mathrm{Z}_{\mathrm{ij}}$ & $\mathrm{W}_{\mathrm{ij}}$ & $\mathrm{S}_{\mathrm{ij}}$ & $\mathrm{C}_{\mathrm{ij}}$ & $\mathrm{Z}_{\mathrm{ij}}$ \\
\hline Zhengzhou & 476.0277 & -179.595 & 4.061942 & 300.494 & 373.1423 & 239.0996 & -81.8044 & 530.4375 \\
\hline Luoyang & 185.2605 & -69.895 & -93.2122 & 22.153 & 124.4978 & 79.77483 & 28.04858 & 232.3212 \\
\hline Sanmenxia & 115.0324 & -43.3993 & 11.05799 & 82.691 & 17.31299 & 11.0937 & -15.6608 & 12.74591 \\
\hline Weinan & 40.49934 & -15.2796 & 10.79772 & 36.017 & 51.95542 & 33.29164 & 2.92853 & 88.17558 \\
\hline Xi'an & 253.2237 & -95.5361 & 109.4959 & 267.183 & 324.8447 & 208.1518 & 85.33086 & 618.3274 \\
\hline
\end{tabular}


We take Zhengzhou-Xian High Speed Railway as the object of case study and can find the data from yearbooks from the cities along this line as in Table 1.

Based on the methodology we developed above, the result can be easily got as in Table 2.

\section{Conclusion}

The following conclusions can be drawn from the study above:

1. The increment of transportation, storage and postal industry in each city is positive, indicating that the opening of Zhengzhou West high speed railway has brought development to the transportation, storage and postal industry in five cities, and the economic increment of Zhengzhou is the highest among the five cities.

2. The increment of real estate industry in each city is positive, indicating that the opening of Zhengzhou West high speed railway has brought development to the real estate industry in five cities, while the economic increment of real estate industry in Xi'an is the highest among the five cities.

3. The competitiveness of transportation, storage and postal industry in Luoyang is negative, indicating that external factors such as the opening and operation of high-speed railway have little dependence on the industry and weak competitiveness.

4. The competitiveness of the real estate industry in Zhengzhou and Sanmenxia is negative, indicating that the opening and operation of high-speed railway and other external factors are less dependent on it and weak competitiveness.

Consequently, the opening of Zhengzhou-Xi'an high speed railway has brought considerable improvements to the industrial agglomeration effect, diffusion effect and regional accessibility. The total benefits created by the agglomeration effect during the construction of Zhengzhou-Xi'an High Speed Railway reached 26.917 billion yuan, including 6.5811 billion yuan for various departments in Henan Province and 20.3361 billion yuan for Shaanxi Province.

In terms of diffusion effect, the opening of Zhengzhou-Xi'an high-speed railway has brought growth to the transportation, storage and postal industry of Zhengzhou, Luoyang, Sanmenxia, Weinan and Xi'an, of which Zhengzhou has benefited the most, with a benefit of 30.4942 billion yuan; Zheng Xi'an high-speed railway has also created economic increment for the real estate industry in five cities, of which Xi'an has the largest increment of 618.3274 yuan.

\section{Acknowledgments}

This research is funded by Major topics of scientific and technological research and development plan of China Railway Zhengzhou Bureau Group Co., Ltd. (Grant number 2020Q2).

\section{References}

[1] Femand Martin. Justifying a High-speed Rail Project: Social Value Vs[J]. Regional Growth, 2000, 31(2): $13-18$.

[2] Blum U, Havnes K E, Karlsson C. Introduction to the Special Issue, The Regional and Urban Effects of High-speed Trains[J]. The Annals of Regional Science,1997,31(1):1-20.

[3] David Ellis. Relationship Between Transportation and the Economy[R]. Beijing Jiao Tong University, 2010.

[4] Tim Lynch. Analysis of the Economic Impacts of Florida High speed Rail[R]. Berlin: Inno Trans. UIC. CCF CER-GEB and UNIFE, 1998.

[5] Reed, J.S. High Speed Rail Related Development in Europe and in the United States[R]. The Development of the HST Station Region Workshop in Taipei.1991.

[6] Jan-Willem Goossens, Stan van Hoesel, Leo Kroon. On solving multi-type railway line planning problems [J]. European Journal of Operational Research, 2006,168(2): 403-42. 
[7] D. O. Eisele. Application of zone theory to a suburban rail transit network[J]. Traffic Quarterly, 1968, 22 (1): 49-53.

[8] A. Schöbel, S. Scholl. Line Planning with Minimal Traveling Time[R]. University of Gottingen. Germany, 2005. 